\title{
P-Stereogenic monophosphines with the 2-p-terphenylyl and1-pyrenyl substituents. Application to Pd and Ru asymmetric catalysis
}

aDepartament de Química Inorgànica, Universitat de Barcelona, Martí i Franquès, 1-11, E-08028, Barcelona, Spain

bDepartament de Cristal lografia, Mineralogia i Dipòsits Minerals, Universitat de Barcelona, Martí i Franquès, s/n, E-08028, Barcelona, Spain

Keywords: P-Stereogenic ligands Pd allylic complexes Ru arene complexes Hydrovinylation Allylic substitution Transfer hydrogenation 
tThe synthesis of five optically pure P-stereogenic monophosphines of the type PPhArR (Ar = 2-pterphenylyl (a), 1-pyrenyl (b); $\mathrm{R}=\mathrm{OMe}, \mathrm{Me}, \mathrm{i}-\mathrm{Pr}$ ) is described. The ligands were fully characterisedand the absolute configurations of $\mathrm{PPh}(1$-pyrenyl)R ( $3 \mathrm{~b}$ and $5 \mathrm{~b} ; \mathrm{R}=\mathrm{OMe}$ and Me respectively) wereconfirmed by X-ray diffraction. The complexation of the monophosphines to $\mathrm{Pd}$ and $\mathrm{Ru}$ organometal-lic units yielded the neutral complexes $[\mathrm{PdCl}(3-2-\mathrm{Me}-\mathrm{allyl}) \mathrm{P}](10-12)$ and $[\mathrm{RuCl} 2($ 6-pcymene)P](16-18). Complete characterisation, including the crystal structure determination of [RuCl2( 6-p-cymene)(PMePh(2-p-terphenyl))] (17a) is provided. Neutral palladium complexes appeared as mixturesof two diastereomers in solution according to NMR. The synthesis and

45 characterisation of four cationic[Pd( 3-2-Me-allyl)(P)2]PF6(13 and 14) is also described. The application of neutral Pd complexes tocatalytic styrene hydrovinylation afforded moderate conversions, high chemoselectivities ( $>92 \%$ ) to 3-phenyl-1-butene and up to $43 \%$ ee with precursor $12 \mathrm{a}$. Cationic Pd complexes were tested as catalyticprecursors in allylic substitution of rac-3-acetoxy-1,3-diphenyl-1propene (rac-I), with the anion ofdimethylmalonate and benzylamine as nucleophiles, obtaining full conversions and up to $80 \%$ ee in alkyl-ation and $60 \%$ ee in amination with precursor 13a. Finally, ruthenium complexes were used as catalyticprecursors in transfer hydrogenation of acetophenone, with 
57 IntroductionThe development of new ligands for enantioselective catalysiswith late transition metals has

58 been the main driving force for thesynthesis of new chiral P(III) compounds for the last decades,

59 sincephosphines and derivatives are known to be ideal ligands to someof the most catalytically active

60 metals [1]. It is well known thatno ligand is ever efficient enough for all the substrates in a particu-lar

61 reaction catalysed by a certain metal. Therefore, optimisation byfine-tuning the steric and electronic

62 properties of the ligands is usu-ally carried out. At present, all sources of chirality are

63 intensivelyexplored and hence a plethora of phosphorus ligands containingstereogenic carbon atoms,

64 axes and planes have been described[1,2].

65 Given the configurational stability of the phosphorus atoms ithas been known for over a century [3] that

66 the $\mathrm{P}$ atom itself canbe a stereogenic element, giving rise to the family of P-stereogenic ligands [4]. This

67

68 type of ligands has a very long history in enantio-selective homogeneous catalysis, which started in the pioneeringworks of Horner [5] and Knowles [6,7] in Rh-catalysed enantiose-lective hydrogenation.

69

70 More recently, the interest in P-stereogenicligands has been rising steadily thanks to new synthetic method-ologies and applications in catalysis $[4,8,9]$.

We also devoted some effort to this field with the preparation ofseries of mono- and diphosphine ligands, which were used in Pd-catalysed reactions (hydrovinylation [10-13] and allylic alkylation[14]) and in Ru-catalysed (cyclopropanation [15] and hydrogentransfer $[15,16]$ ) enantioselective reactions. Although the opticallypure monophosphine ligands were initially obtained by resolutionof the racemic mixtures by means of Pd complexes [10,11], theyhave more recently obtained by methods based on asymmetric syn-thesis due to its superior versatility. Therefore, P-ligands obtainedby the so-called Evans [17] and the Jugé-Stephan [18] methods havebeen reported. In particular, series of ligands prepared by the Jugé-Stephan method with the general structure depicted in Fig. 1 weredescribed [12,14]

The monophosphine ligands, which contained a phenyl, a poly-cyclic aromatic group and a methoxy or an alkyl group were complexed to $\mathrm{Pd}$ and $\mathrm{Ru}$ organometallic moieties. The obtainedcomplexes shown in the figure were employed to the catalyticreactions mentioned before. Some of the phosphines, in particularthose bearing the 2-biphenylyl group, were found to be competentligands $[12,14,16]$.

In this paper, the extension of these studies with new phos-phines bearing the 2-p-terphenylyl (a) and 1pyrenyl (b) groups, rarely found in the literature, chosen with the aim of improvingthe performance of the previous generation of ligands is reported.To the best of our knowledge, the only monophosphine reportedto date that contains the unsubstituted 2-p-terphenylyl group isthe racemic phenyl(2-pterphenylyl)phosphine oxide [19]. Severalachiral hydroxyterphenylylphosphines have been described andsuccessfully used as ligands in Pd-catalysed cross-coupling reac-tions [20-22] and also extremely bulky phosphines containing a2,3,4,5-tetraphenyl moiety have been reported and used in severalPdcatalysed reactions $[23,24]$. Finally, a few achiral diphosphines, built around the terphenylyl skeleton, are also known [25-28].Regarding the 1-pyrenyl substituent, 1-diphenylphosphinopyrenehas been described 92 [29]. 


\section{RESULTS AND DISCUSSION}

\subsection{Ligand synthesis}

From our previous studies [12,13,30] and from others [31,32],it is known that standard Jugé-Stephan [18] procedure isvery well suited to prepare P-stereogenic phosphines bearingo-monosubstituted aryl fragments. The introduction of the o-monosubstituted aryl fragment it is carried out via organolithiumsand therefore it is mandatory to have the suitable precursors toprepare such species. In the present case, the most obvious pre-cursors are the corresponding aryl bromides 2-bromo-pterphenyl(Bra) and 1-bromopyrene (Brb), which can be easily lithiated withn-butyllithium at low temperatures (Scheme 1).

Following a literature precedent [33], the preparation ofBra was carried out by Suzuki-Miyaura coupling betweenp-biphenylylboronic acid and o-bromoiodobenzene, using[Pd2(dba)3]/PPh3as catalytic precursor and aqueous $\mathrm{Na} 2 \mathrm{CO} 3$ solution as a base. After some optimisation, Bra could be obtainedas a crystalline solid in good yield. Compound Brb was also prepared with a modified literature method [34], based on thedirect bromination of pyrene with NBS in DMF. This method isvery selective towards the monobromination in position 1 and Brbcould be obtained in high yield with enough purity to be employedin the synthesis of the phosphines. With the bromoarene precur-sors in hand, the Jugé-Stephan methodology was followed to haveaccess to the desired ligands (Scheme 2).

The regioselective ring opening of oxazaphospholidine-borane 1 was initially attempted preparing the organolithiums Lia and Libin Et2O at $-78^{\circ} \mathrm{C}$ as in previous reports [12,35]. It was found, how-ever, that the very low solubility of these species, probably dueto the extensive conjugation of the aryl groups employed, led tolow yields of 2 and the recovery of large quantities of unreacted 1.Therefore, Et $2 \mathrm{O}$ was switched to THF, in which the organolithiumdid not precipitate. With this modification, 1 was completely con-sumed and good yields of 2 could be obtained. The ring opening wasvery clean with organolithium Lib but, in contrast, Lia led to severalbyproducts as judged by31P spectroscopy. Phosphamide-borane 2afeatured a broad singlet at $70.2 \mathrm{ppm}$ and another two peaks werealso present at 133 and $107 \mathrm{ppm}$. The signal at higher field could beassigned to the product 9, originated by basepromoted eliminationon 1 instead of the expected substitution at the $\mathrm{P}$ atom (Scheme 3).

This elimination reaction has been described previously in theliterature [36] when bulky organolithium reagents are employed.In the case described, it also leads to 1,4-diphenylbenzene, whichcould indeed be recovered during the purification of $2 \mathrm{a}$. It wasfound that this compound and the other unidentified one reactedin the subsequent reactions and the formed byproducts could notbe separated from the desired intermediates. Therefore, the opti-misation of the ring-opening step was mandatory. After someexperimentation, it was discovered that by simply carrying out thereaction in more diluted conditions was enough to maximise theformation of the desired phosphamide-borane $2 \mathrm{a}$ and minimise thequantities of impurities to an acceptable level.

Following the standard procedure, acid-mediated methanolysisof 2 produced the corresponding phosphinite-boranes 3 in goodyields. Whereas $3 \mathrm{a}$ was a dense colourless oil, $3 \mathrm{~b}$ was a yellow solidthat precipitated as a pure product during the methanolysis step.

Solutions of phosphinite boranes 3 in Et2O were treatedat low temperature with $\mathrm{RLi}(\mathrm{R}=\mathrm{Me}$, i-Pr and t$\mathrm{Bu}$ ) to obtainmonophosphine-boranes 5 and 6 . As expected [12] the bulkyt-Bu group could no be introduced according to31P NMR spectroscopy. Depending on the exact reaction conditions, thepeak of the starting phosphinite-boranes 3 (at 1 around $+110 \mathrm{ppm}$ )and/or multiple peaks indicating decomposition could be detected.The less bulky i-Pr group could be successfully introduced by reac-tion of i-PrLi with 3a but once again starting phosphinite-boraneand/or multiple peaks were observed when $3 \mathrm{~b}$ was employed.These results are in line with previously published data [12] indi-cating that the 
introduction of a conjugated aromatic substituentin the ring-opening step of the Jugé-Stephan method precludes theintroduction of the t-Bu group and sometimes even the i-Pr group.The protected phosphinite and phosphine ligands were air-stableoils (for Ar = 2-p-terphenylyl) or solids (for Ar $=1$ pyrenyl), whichwere characterised by the usual techniques. HPLC analysis on a chi-ral column of the crude products showed that they were present asoptically pure (ee $>95 \%$ ) products. Single crystals, suitable to per-form X-ray diffraction studies, were obtained for $3 \mathrm{~b}$ and $5 \mathrm{~b}$. Themolecular structures for the two compounds are displayed in Fig. 2.

The crystal structures confirmed that the absolute configura-tions of the $\mathrm{P}$ atom were $\mathrm{R}$ for $3 \mathrm{~b}$ and $\mathrm{S}$ for $5 \mathrm{~b}$, as expectedgiven the enantiomer of ephedrine employed to prepare $3[(1 \mathrm{R}, 2 \mathrm{~S})-(-)$-ephedrine] and the stereochemical course of each ofthe Jugé-Stephan method steps [18]. Distances and angles ofboth borane adducts were similar to other previously reportedphosphine-boranes [12,16,37]. A parameter that allows the eval-uation of the steric hindrance of the ligand is the mean value ofthe three BPC angles. The smaller the value, the higher the sterichindrance of the ligand. In the present case, the values are 112.88 for $3 \mathrm{~b}$ and 113.46 for $5 \mathrm{~b}$, meaning that the former is slightly morebulky than the latter. Both values are in the range observed for otherP-stereogenic phosphine-boranes [12,37]. Borane adducts 3,5 and6 were conveniently deprotected by neat morpholine at room tem-perature [12,37], affording the free phosphinites (4a and $4 b$ ) andphosphines $(7 \mathrm{a}, 7 \mathrm{~b}$, and $8 \mathrm{a}$ ) ready for complexation.

\subsection{Neutral Pd complexes}

160

Neutral Pd allylic complexes of the type $[\mathrm{PdCl}(3-(2-$ Methylallyl)(P)] (10-12), were easily prepared by the standardmethod, consisting of splitting Pd dimer D1 with two equivalentsof the ligands in dichloromethane at room temperature (Scheme 4)[12].

The complexes were obtained as air-stable pale yellow solids.The analysis of the NMR spectra in $\mathrm{CDCl} 3$ indicated that, asexpected, they were present as mixtures of two diastereomericspecies, because of the presence of one chiral phosphine and theallyl moiety. Accordingly, two sharp singlets were present in the31P NMR spectra and duplication of the allylic peaks was clearlyobservable in the $1 \mathrm{H}$ NMR spectra. It has to be pointed out that thepresence of the chiral phosphine ruled out the presence of any sym-metry element and hence in principle $\mathrm{H}$ and $\mathrm{C}$ atoms of the eachdifferent isomer were all different. The proportion of each isomeris indicative of the discrimination ability of the chiral ligand in the neutral complexes. The isomeric ratio was 1:1 for complexes bear-ing the phosphines with the 1pyrenyl group (10b and 11b) andfor complex 10a. In contrast, it was around 1:2 for complexes 11aand $12 \mathrm{a}$, similarly to complexes with phosphines containing the2-biphenylyl group [12].

\subsection{Cationic Pd complexes}

Cationic Pd allylic complexes of the type [Pd( 3-(2-Methylallyl)(P)2]PF6(13-15), were easily prepared followinga previously reported method [14]. Thus, dimer D1 dissolved indichloromethane was treated with four equivalents of monophos-phine in the presence of excess of ammonium hexafluorophosphate (Scheme 5).

An aqueous final work-up allowed the isolation of the desiredcationic complexes as air-stable solids. In solution they slowlydecomposed to Pd black and other unknown species as31P NMRspectroscopy evidenced. This process was faster for complexes withphosphines containing the 2-p-terphenylyl group (13a and 14a).The complexes are present as single species in solution but the chi-rality of the phosphine makes each phosphine and each half of theallyl group to appear different in the NMR spectra. For that reason, two sharp doublets $(\mathrm{JPP}=29-55 \mathrm{~Hz})$ with strong roof effect wereobserved in the31P NMR spectra and four resonances assignable tothe allylic protons could be seen. Two of them, corresponding 
to theanti protons, appeared as sharp doublets $(\mathrm{JPP}=9-13 \mathrm{~Hz})$ whereasthe remaining two appeared as broad singlets and corresponded to the two syn protons. In contrast to 13 and 14, solutions of complex15a displayed only two peaks in the31P NMR spectrum and sev-eral peaks belonging to the i-Pr and the allylic moieties in the1HNMR spectrum, which could not be assigned. It is possible the bulkiness of the phosphine 8a precludes the appropriate coordinationof two ligands to stabilise 15a. This complex was not further usedin catalysis.

\section{4. $\mathrm{Ru}$ complexes}

Similarly to the Pd complexes discussed above, neutral Rucomplexes of the type [RuCl2( 6-(pcymene)(P)] (16-18), wereprepared by splitting the well-known Ru dimer D2 with two equiv-alents of the appropriate phosphorus ligand (Scheme 6) $[15,38]$.

The desired complexes were obtained as air-stable red solidsafter recrystallisation. In solution they were conveniently charac-terised by NMR. They featured a singlet in the31P NMR spectra. In1H and13C NMR spectra, the chirality of the phosphine made allthe $\mathrm{H}$ and $\mathrm{C}$ atoms of the coordinated aryl moiety of the p-cymeneto appear differentiated as well as the two methyl groups of theisopropyl substituent.

Suitable monocrystals to perform X-ray diffraction studies couldbe obtained for 17a. Its ORTEP representation is displayed in Fig. 3.

The complex shows the typical "piano-stool" pseudotetrahedralgeometry around the Ru atom with the pcymene ring coordi-nated in 6 fashion, making the Ru to adopt a distorted octahedralcoordination environment. The structure allows an additional con-firmation of the absolute configuration of the phosphorus atom ofthe phosphine ( $\mathrm{S}$, as a free ligand). The geometric parameters ofthe structure are similar to other previously reported $[\mathrm{RuCl} 2(6$-p-cymene $)(\mathrm{P})]$ complexes $[15,16,39]$. As expected, the two Ru-Cldistances are very similar and that the imaginary line defined bythe two $\mathrm{Cl}$ atoms is approximately parallel to the line defined bythe substituted carbons of the p-cymene ring. The average dis-tance between $\mathrm{Ru}$ and each of the six aromatic carbon atoms ofthe p-cymene ring is $2.218^{\circ} \mathrm{A}$. These distances can be divided in twogroups: the relatively short ones (those involving the three $\mathrm{C}$ atomscloser to the phosphine, average distance of $2.203^{\circ} \mathrm{A}$ ) and the rel-atively long ones (those involving the three $\mathrm{C}$ atoms further awayfrom the phosphine, average distance of $2.232^{\circ} \mathrm{A}$ ).

\subsection{Asymmetric hydrovinylation}

Catalytic hydrovinylation can be viewed as the heterocodimeri-sation between an activated olefin and ethylene catalysed by atransition metal complex, usually based on Ni or Pd [40,41]. Theinterest in this reaction is steadily increasing, especially regardingthe asymmetric version [41-43]. The model vinyl arene substrateused was styrene with neutral Pd complexes 10-12 as catalyticprecursors (Scheme 7).

The desired hydrovinylation product, 3-phenyl-1-butene, is achiral compound amenable to enantioselection. The Pd catalyticspecies, however, are also active in isomerising it to achiral (E/Z)-3phenyl-2-butenes. Other typically encountered byproducts in small amounts are those arising from the dimerisation of eitherethylene (1-butene) or styrene (1,3-diphenyl-1-butenes). The mainchallenge of the hydrovinylation reactions is the design of ligandscapable of forming catalytic precursors leading to high chemo- andenantioselectivities of the hydrovinylation product [41]. With Niand Pd systems, the ligand, usually with $\mathrm{P}$ as a donor atom, hasto be monodentate due to the particularities of the catalytic cycle[41] a feature that makes more challenging the design of efficientligands.

Previous research carried out with monophosphines $\operatorname{PArPhR}(\mathrm{Ar}=1$-naphthyl, 9-phenanthryl, 2biphenylyl; $\mathrm{R}=\mathrm{OMe}, \mathrm{Me}$, i-Pr)led to some selective catalysts towards 3-phenyl-1-butene in 
thehydrovinylation of styrene $[12,13,30]$. In this paper, these resultscan be conveniently compared to those obtained with the catalyticprecursors based on the 2-p-terphenylyl and 1-pyrenyl phosphinespresented here. The results are given in Table 1.

As expected, all neutral allylic complexes are active in catalytichydrovinylation with very different activities depending on thesubstituents at the $\mathrm{P}$ atom, as clearly evidenced by the TOF values at $6 \mathrm{~h}$. The order of increasing activity is $10 \mathrm{a}<11 \mathrm{a}<11 \mathrm{~b}<12 \mathrm{a}<11 \mathrm{~b}$. Infact, precursor $11 \mathrm{~b}$ leads to a very fast catalytic system so in orderto avoid extensive isomerisation of 3-phenyl-1-butene the reactiontime had to be shortened (cf. entries 4 and 5). The catalytic systemsare very selective towards the primary $[-$ hydrovinylation product,namely 3-phenyl-1-butene, which is higher than $92 \%$ at moderateconversions (entries 2 and 6). Regarding the enantioselectivity, onlythe systems containing the 2-p-terphenylyl substituent in the phos-phine lead to some enantioenriched 3-phenyl-1-butene (entries 1,3 and 6). As no secondary interaction can be envisaged with thiskind of ligands, the moderate enantioselectivities obtained can beexplained by pure steric differentiation [12]. In this regard, the lin-earity of the 2-pterphenylyl group in the monophosphorus ligandsis clearly better to the planarity of the 1-pyrenyl substituent.

The comparison these results with previously published datawith similar phosphines $[12,13,30]$ show that overall the activi-ties are somewhat lower for the phosphines discussed here. Theselectivities are maintained whereas the enantioselectivities of theprecursors with phosphines bearing the 2-pterphenylyl group arevery similar to those of the precursors with phosphines bearing the2-biphenylyl group $[12,30]$. These results show that the introduc-tion of an extra phenyl ring at the end of the 2biphenylyl moietydoes not improve the performance of the ligands, pointing outthat probably it situates in a position too far away from the cat-alytically active Pd centre to have any remarkable effect. The factthat the 1-pyrenyl-containing phosphine ligands generate precur-sors that give to racemic 3-phenyl1-butene (compared to up tothe $22 \%$ ee obtained with the 1-naphthyl-containing phosphines[12]), demonstrates that this substituent is not adequate for theasymmetric hydrovinylation of styrene.

\subsection{Pd-catalysed allylic substitution}

Allylic substitution reactions can be defined as the substitutionof a leaving group, located in an allylic position, by an incomingnucleophile, catalysed by a catalytic precursor very often basedon Pd. Its asymmetric version has been thoroughly studied andapplied to numerous natural product syntheses [44] and it iscommonly used to test the performance of new bidentate chi-ral ligands [45]. One of the model substrates in this reactions isracemic trans-1,3-diphenyl-2-propen-1-acetate (1,3-diphenylallylacetate), rac-I, and two of the nucleophiles of reference arethe anion derived from dimethyl malonate and benzylamine(Scheme 8).

Cationic Pd complexes (usually prepared in situ) of the type[Pd( 3-allyl)(PP)]X (PP = chiral diphosphine, two monodentatephosphines or in general a bidentate ligand) are the usual precursors in this type of transformation. In order to compare [14] the effect of the modification of the phosphine substituents onthe catalytic outcome, the performance of complexes 13 and 14in asymmetric allylic substitutions was explored. The results aregiven in Table 2.

Regardless of the substituents of the phosphine, all the cationiccomplexes were active both in alkylation and amination of rac-I,leading to quantitative conversions to the substituted product after $24 \mathrm{~h}$ of reaction time. The enantioselectivities were found to be verydependent on the ligand. It can be seen that phosphines containingthe 1-pyrenyl substituent (entries 3, 4, 7 and 8) are clearly not agood choice for allylic substitutions on rac-I, since they give verylow chiral induction in the products. More interesting results areobtained with precursors with phosphines $\mathrm{PPh}(2$-p-terphenylyl)R(entries 1, 2, 5, 6). For both substitution reactions racemic productsare obtained for $\mathrm{R}=\mathrm{Me}$ (entries 2 and 6) whereas good enantiose-lectivities are achieved for $\mathrm{R}=\mathrm{OMe}$ (entries 1 and 5). These resultsare slightly better but 
278 follow the same trend than those previouslypublished with 2-biphenylyl containing monophosphines in 279 allylicalkylation [14].

\subsection{Ru-hydrogen transfer}

282 In hydrogen transfer reactions, a carbonyl from a ketone isreduced to the parent alcohol by a hydrogen 283 donor, usually analcohol, under $\mathrm{Ru}$ or Ir catalysis [46,47]. These reactions areinteresting because they 284 avoid using hydrogen gas or dangerousmetallic hydrides to reduce the ketone. In the asymmetric ver285 sion [46,48-50], the model substrate is undoubtedly acetophenone, dissolved in isopropanol as hydrogen 286 donor (Scheme 9).

287 Although they are not the most typically used precursors, com-plexes of the type [RuCl2( 6-p288 cymene)P] $(\mathrm{P}=$ monophosphorusligand $)$ in the presence of a base, are known to be active in 289 hydrogentransfer reactions [15,16,38,51]. Following previous studies withanalogous complexes, the 290 performance of complexes 16-18 wasstudied. The results are given in Table 3.

291 All catalytic precursors are active in the reaction at reflux ofisopropanol in the present of excess of t$292 \mathrm{BuOK}$, after activating thesystem for $15 \mathrm{~min}$ in the absence of acetophenone. Full conversionswere 293 obtained in all cases after 24 of reaction time except for $17 b$ (entry 5). Interestingly, the conversions at 294 the same reaction timesare all very similar except for $16 \mathrm{~b}$ (entry 4), which is considerablyfaster than the rest. This result is in contrast to previously publishedseries of similar ligands, for which phosphines always led to fasterprecursors compared to the parent phosphinites [15]. On the enan-tioselectivities side, very low enantioselectivities were obtained forthe five precursors. In this case, the elongation of the 2-biphenylylsubstituent is very detrimental to enantioselectivity since precur-sor containing the phosphine $\mathrm{P}(\mathrm{i}-\mathrm{Pr}) \mathrm{Ph}$ (2-biphenylyl) [15] leads toa $45 \%$ ee under the same conditions but precursor containing thephosphine $\mathrm{P}(\mathrm{i}-\mathrm{Pr}) \mathrm{Ph}(2-\mathrm{p}$-terphenylyl) leads to only $12 \%$ ee (entry3). A possible explanation is that the long 2-p-terphenylyl moietyforces the phosphine to direct the substituents far away from theRu centre as it is observed in the crystal structure of 17 a describedabove. 
313 ConclusionsIn conclusion, the successful preparation of P-stereogenic phos-phines containing a bulky 2-

314 p-terphenylyl or 1-pyrenyl groupby the Jugé-Stephan method has been described. The new lig-ands have 315 been used to prepare and characterise three families oforganometallic complexes: neutral Pd allylic 316 complexes (10-12), cationic Pd allylic complexes (13 and 14) and neutral Ru p-cymenecomplexes (16317 18). Neutral Pd complexes have been used incatalytic hydrovinylation of styrene with good chemo- and 318 regiose-lectivity results for all the ligands and a moderate enantioselectivity(43\% ee) with 12a. Cationic 319 Pd complexes have been used in cat-alytic allylic substitutions on rac-I, reaching full conversions 320 bothfor alkylations and aminations, with up to $80 \%$ ee in allylic alkyl-ation and up to $60 \%$ in amination 321 with complex 13a. Finally, Rucomplexes have been used in hydrogen transfer reactions withgood 322 activities but very low enantioselectivities.

323 The best enantioselectivities have been invariably obtained withligands containing the 2-p-terphenylyl 324 group. In spite of this, thebest enantioselectivities are only marginally better than those withphosphines 325 containing the 2-biphenylyl group and the overall cat-alytic performance of the presented ligands is not 326 significantlybetter than previous results with phosphines with smaller sub-stituents $[12,14,15]$. 


\subsection{Hydrovinylation reactions}

Hydrovinylation reactions were carried out in a stainless-steelautoclave fitted with an external jacket connected to an ethanolbath and the temperature controlled using a thermostat to $\pm 0.5^{\circ} \mathrm{C}$. The internal temperature was controlled with a thermocouple. ThePd precursor $(0.01 \mathrm{mmol})$, styrene $(1.04 \mathrm{~g}, 20$ $\mathrm{mmol})$ and $\mathrm{AgBF} 4(2.1 \mathrm{mg}, 0.011 \mathrm{mmol})$ were dissolved in $15 \mathrm{~mL}$ of dichloromethaneand stirred for 10 min, protected from light. After filtering off the $\mathrm{AgCl}$ formed, the solution was quickly placed, by syringe, into theautoclave, which had been purged by successive vacuum/nitrogencycles and thermostated to $25^{\circ} \mathrm{C}$. Ethylene was admitted until apressure of around 15 bar was reached. After the allotted time, theautoclave was slowly depressurised and $10 \mathrm{~mL}$ of a $10 \%$ aqueous $\mathrm{NH} 4 \mathrm{Cl}$ solution was added. The mixture was stirred for $10 \mathrm{~min}$ inorder to quench the catalyst. The organic layer was separated, driedwith $\mathrm{Na} 2 \mathrm{SO} 4$, filtered through a plug of SiO2and subjected to GCanalysis.

\subsection{Allylic substitutions with dimethyl malonate}

Under a nitrogen atmosphere, the appropriate Pd precur-sor $(0.01 \mathrm{mmol})$, trans-1,3-diphenyl-2-propen1-acetate (rac-I,1 mmol), dimethyl malonate $(3 \mathrm{mmol})$, BSA $(3 \mathrm{mmol})$ and $\mathrm{KOAc}(1 \mathrm{mg})$ were dissolved, in this precise order, in $4 \mathrm{~mL}$ ofdichloromethane. The flask was covered with an aluminium foiland left stirring for the allotted time. In order to quench thereaction, diethyl ether $(20 \mathrm{~mL})$ and aqueous $10 \%$ ammonium chlo-rides solution $(20 \mathrm{~mL})$ were added. After extraction, the organicphase was dried with anhydrous sodium sulfate, filtered and thesolvents removed in vacuo. The crude was analysed by $1 \mathrm{H}$ NMRin order to estimate the conversion. The crude was dissolved indichloromethane and passed trough a column of silica to removethe metallic impurities. The eluent was removed in vacuo and theresidue was analysed by NMR and HPLC.

\subsection{Allylic substitutions with benzylamine}

Under a nitrogen atmosphere, the Pd precursor (0.01 mmol),trans-1,3-diphenyl-2-propen-1-acetate (racI, $1 \mathrm{mmol})$ and benzy-lamine $(3 \mathrm{mmol})$ were dissolved, in this precise order, in $4 \mathrm{~mL}$ ofdichloromethane. The flask was covered with an aluminium foiland left stirring for the allotted time. In order to quench the reac-tion, diethyl ether $(20 \mathrm{~mL})$ and aqueous $10 \%$ ammonium chloridesolution $(20 \mathrm{~mL})$ were added. After extraction, the organic phasewas dried with anhydrous sodium sulfate, filtered and the solventsremoved in vacuo. The eluent was removed in vacuo and the residuewas analysed by NMR and HPLC.

\subsection{Transfer hydrogenation reactions}

A $50 \mathrm{~mL}$ schlenk flask was charged with the ruthenium precursor $(0.02 \mathrm{mmol})$ and potassium tertbutoxide $(11.2 \mathrm{mg}, 0.1 \mathrm{mmol})$ andwas purged with three vacuum/argon cycles. Under a gentle flowof argon, $25 \mathrm{~mL}$ of 2-propanol were added and the flask heated toreflux $\left(85^{\circ} \mathrm{C}\right)$ for $15 \mathrm{~min}$. After that time acetophenone $(0.468 \mathrm{~mL}, 4.0 \mathrm{mmol})$ was rapidly added to start the catalytic run. The reactionwas monitored at the allotted times by taking aliquots of around $0.1 \mathrm{~mL}$ and analysing them by GC. 
371 The authors thank the Ministerio de Ciencia e Innovación(MICINN, grant number CTQ2010-15292) for 372 financial support ofthis work. We also thank Dr. Sebastian Gischig for the crystalstructure determination 373 of $3 \mathrm{~b}$ performed at the Department ofChemistry, ETH Hönggerberg, Zürich, Switzerland. 


\section{REFERENCES}

[1] A. Börner (Ed.), Phosphorus Ligands in Asymmetric Catalysis: Synthesis andApplications, Wiley-VCH, Weinheim, 2008.

[2] P.C.J. Kamer, P.W.N.M. van Leeuwen (Eds.), Phosphorus(III) Ligands in Homo-geneous Catalysis: Design and Synthesis, Wiley, 2012.

[3] J. Meisenheimer, L. Lichtenstadt, Chem. Ber. 44 (1911) 356-359.

[4] A. Grabulosa, P-Stereogenic Ligands in Enantioselective Catalysis, Royal Societyof Chemistry, Cambridge, 2011.

[5] L. Horner, H. Siegel, H. Büthe, Angew. Chem. Int. Ed. 7 (1968) 942

.[6] W.S. Knowles, M.J. Sabacky, Chem. Commun. (1968) 1445-1446.

[7] W.S. Knowles, Angew. Chem. Int. Ed. 41 (2002) 1998-2007.

[8] K.M. Pietrusiewicz, M. Zablocka, Chem. Rev. 94 (1994) 1375-1411.

[9] A. Grabulosa, J. Granell, G. Muller, Coord. Chem. Rev. 251 (2007) 25-90

[10] J. Albert, J.M. Cadena, J.R. Granell, G. Muller, J.I. Ordinas, D. Panyella, C. Puerta,C. Sañudo, P. Valerga, Organometallics 18 (1999) 3511-3518

[11] J. Albert, R. Bosque, J. Magali Cadena, S. Delgado, J.R. Granell, G. Muller, J.I.Ordinas, M. Font Bardia, X. Solans, Chem. Eur. J. 8 (2002) 2279-2287.

[12] A. Grabulosa, G. Muller, J.I. Ordinas, A. Mezzetti, M.A. Maestro, M. Font-Bardia,X. Solans, Organometallics 24 (2005) 4961-4973.

[13] A. Grabulosa, A. Mannu, G. Muller, T. Calvet, M. Font-Bardia, J. Organomet.Chem. 696 (2011) $2338-2345$.

[14] A. Grabulosa, G. Muller, R. Ceder, M.A. Maestro, Eur. J. Inorg. Chem. (2010)3372-3383.

[15] A. Grabulosa, A. Mannu, A. Mezzetti, G. Muller, J. Organomet. Chem. 696 (2012)4221-4228.

[16] R. Aznar, A. Grabulosa, A. Mannu, G. Muller, D. Sainz, V. Moreno, M. Font-Bardia,T. Calvet, J. Lorenzo, Organometallics 32 (2013) 2344-2362

.[17] A.R. Muci, K.R. Campos, D.A. Evans, J. Am. Chem. Soc. 117 (1995) 9075-9076.

[18] S. Jugé, M. Stephan, J.A. Laffitte, J.P. Genêt, Tetrahedron Lett. 31 (1990)6357-6360 
.[19] Y. Kuninobu, T. Yoshida, K. Takai, J. Org. Chem. 76 (2011) 7370-7376.

[20] S. Ishikawa, K. Manabe, Chem. Lett. 36 (2007) 1302-1303.

405

[21] S. Ishikawa, K. Manabe, Tetrahedron 66 (2010) 297-303.

406

[22] M. Yamaguchi, H. Katsumata, K. Manabe, J. Org. Chem. 78 (2013) 9270-9281.

407

[23] T. Iwasawa, T. Komano, A. Tajima, M. Tokunaga, Y. Obora, T. Fujihara, Y. Tsuji,Organometallics 25 (2006) 4665-4669.

[24] Y. Akai, T. Yamamoto, Y. Nagata, T. Ohmura, M. Suginome, J. Am. Chem. Soc.134 (2012) 11092-11095.

[25] A. Velian, S. Lin, A.J.M. Miller, M.W. Day, T. Agapie, J. Am. Chem. Soc. 132 (2010)62966297.

[26] S. Lin, M.W. Day, T. Agapie, J. Am. Chem. Soc. 133 (2011) 3828-3831.

[27] S. Lin, D.E. Herbert, A. Velian, M.W. Day, T. Agapie, J. Am. Chem. Soc. 135 (2013)1583015840

[28] S. Suseno, K.T. Horak, M.W. Day, T. Agapie, Organometallics 32 (2013)6883-6886.

[29] J. Hu, J.H.K. Yip, D.-L. Ma, K.-Y. Wong, W.-H. Chung, Organometallics 28 (2009)51-59.

[30] L. Rodríguez, O. Rossell, M. Seco, A. Grabulosa, G. Muller, M. Rocamora,Organometallics 25 (2006) 1368-1376.

[31] S. Rast, M. Stephan, B. Mohar, Tetrahedron Lett. 53 (2012) 6815-6818.

[32] B. Mohar, A. Cusak, B. Modec, M. Stephan, J. Org. Chem. 78 (2013) 4665-4673.

[33] S. Moon, H. Yoon, Y. Kang, Acta Cryst. E66 (2010) o743.

[34] R.H. Mitchell, Y. Lai, R.V. Williams, J. Org. Chem. 44 (1979) 4733-4735.

[35] U. Nettekoven, P.C.J. Kamer, P.W.N.M. van Leeuwen, M. Widhalm, A.L. Spek, M.Lutz, J. Org. Chem. 64 (1999) 3996-4004

.[36] M. Stephan, D. Sterk, B. Modec, B. Mohar, J. Org. Chem. 72 (2007) 8010-8018.

[37] R.M. Stoop, A. Mezzetti, F. Spindler, Organometallics 17 (1998) 668-675.

[38] A. Grabulosa, A. Mannu, E. Alberico, S. Denurra, S. Gladiali, G. Muller, J. Mol.Catal. A: Chem. 363-364 (2012) 49-57.

[39] J. Wolf, K. Thommes, O. Briel, R. Scopelliti, K. Severin, Organometallics 27 (2008)4464-4474. 
431 [40] T.V. RajanBabu, Synlett (2009) 853-885.

432 [41] G. Muller, A. Grabulosa, M. Rocamora, R.M. Ceder, Catal. Sci. Technol. 3 (2013)1446-1464.

433 [42] T.V. RajanBabu, Chem. Rev. 103 (2003) 2845-2860.

434 [43] T.V. RajanBabu, C.R. Smith, in: E.M. Carreira, Y. Hisashi (Eds.), ComprehensiveChirality, $435 \quad$ Elsevier, Amsterdam, 2012, pp. 355-398

436 [44] B.M. Trost, M.L. Crawley, Chem. Rev. 103 (2003) 2921-2943

437 [45] B.M. Trost, D.L. van Vranken, Chem. Rev. 96 (1996) 395-422.

438 [46] G. Zassinovich, G. Mestroni, S. Gladiali, Chem. Rev. 92 (1992) 1051-1089.

439 [47] D. Klomp, U. Hanefeld, J.A. Peters, in: J.G. de Vries, C.J. Elsevier (Eds.), Handbookof $440 \quad$ Homogeneous Hydrogenation, Wiley-VCH, Weinheim, 2007, pp. 585-630.

441 [48] R. Noyori, S. Hashiguchi, Acc. Chem. Res. 30 (1997) 97-102.

442 [49] S. Gladiali, E. Alberico, Chem. Soc. Rev. 35 (2006) 226-236.

443 [50] A.J. Blacker, in: J.G. de Vries, C.J. Elsevier (Eds.), Handbook of HomogeneousHydrogenation, $444 \quad$ Wiley-VCH, Weinheim, 2007, pp. 1215-1244.

445 [51] L. Wang, Q. Yang, H.-Y. Fu, H. Chen, M.-L. Yuan, R.-X. Li, Appl. Organometal.Chem. 25 $446 \quad$ (2011) 626-631. 
450 Figure 1. P-stereogenic monophosphines and their derived Pd and Ru complexes.

451

452

Scheme 1. Synthesis of Bra, Brb, Lia and Lib.

453

Scheme 2. Synthesis of the P-stereogenic ligands.

Scheme 3. Reaction of 1 with Lia.

Figure 2. ORTEP representation of the molecular structures of $3 \mathrm{~b}$ (left) and $5 \mathrm{~b}$ (right). Hydrogen atoms have been omitted for clarity. Selected distances $(\AA)$ and angles ( $\left.{ }^{\circ}\right)$ for3b: P1-O1, 1.6005(14); P1-C17, 1.7934(19); P1-C1, 1.8081(19); P1-B1, 1.899(2); C23-O1, 1.443(2); B1-P1-O1, 115.54(10); B1-P1C17, 110.06(10); B1-P1-C1, 113.04(10).For 5b: P1-C23, 1.804(3); P1-C17, 1.819(2); P1-C1,

Scheme 4. Synthesis of complexes 10-12.

465

Scheme 5. Synthesis of complexes 13-15.

Scheme 6. Synthesis of complexes 16-18.

469

470

Fig. 3. ORTEP representation of $17 \mathrm{a}$. Thermal ellipsoids drawn at $50 \%$ proba-bility level. Hydrogen atoms have been omitted for clarity. Distances $(\AA)$ andangles ( $\left.{ }^{\circ}\right): \mathrm{Ru}(1)-\mathrm{Cl}(1): 2.4115(8) ; \mathrm{Ru}(1)-\mathrm{Cl}(2)$ : $\mathrm{Cl}(1)-\mathrm{Ru}(1)-\mathrm{Cl}(2): 89.90(3)$.

475

Scheme 7. Styrene hydrovinylation

Scheme 8. Allylic substitution reactions on rac-I.

Scheme 9. TH of actophenone. 


$$
\text { ... }
$$


<smiles>O=[W]Oc1ccc(-c2ccccc2)cc1</smiles>

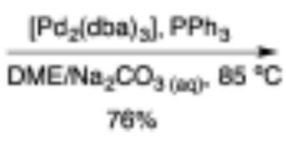<smiles>Brc1ccccc1-c1ccc(-c2ccccc2)cc1</smiles><smiles></smiles>

Bra<smiles></smiles>

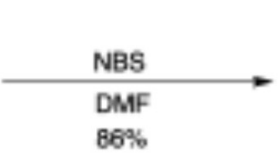<smiles>Brc1ccc2ccc3cccc4ccc1c2c34</smiles><smiles>Clc1ccccc1-c1ccc(-c2ccccc2)cc1</smiles>

Lia<smiles>c1cc2ccc3cccc4ccc(c1)c2c34</smiles> 
494

495

496

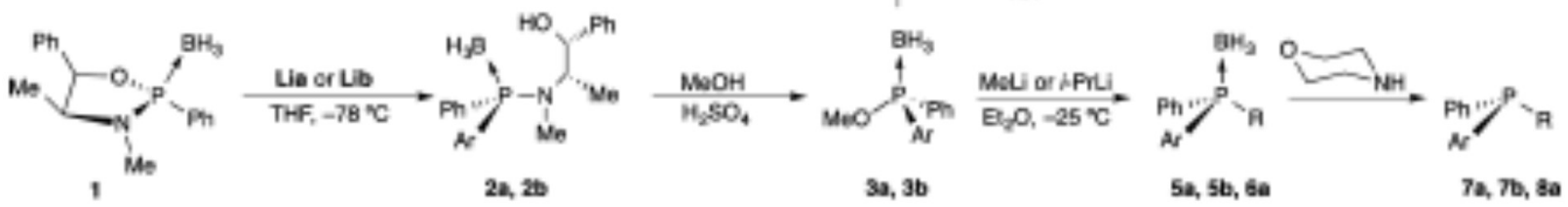


499

500
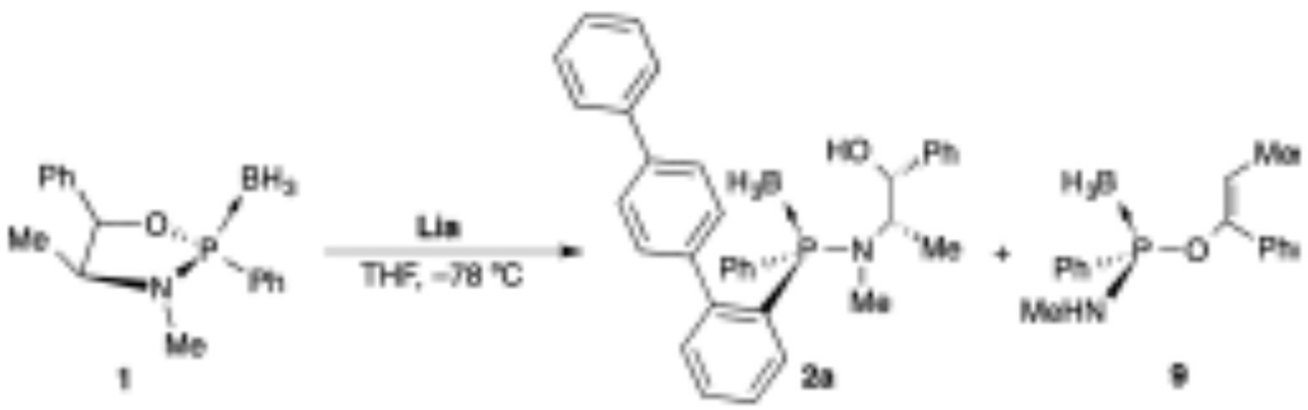

501

502 


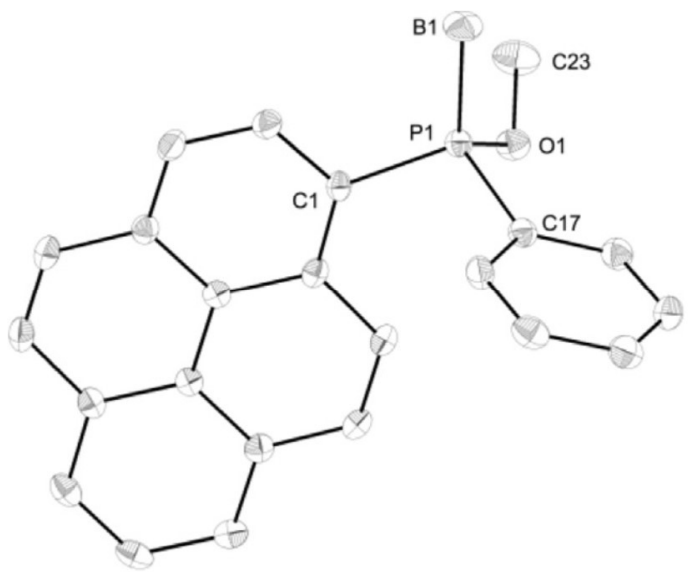

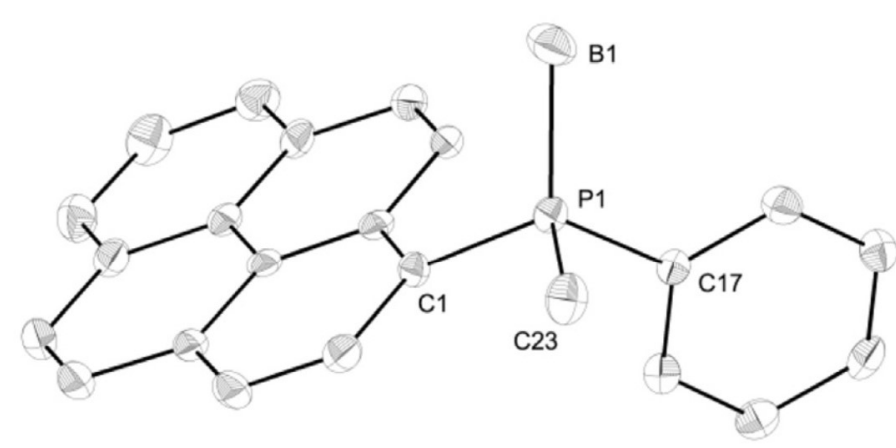

507 


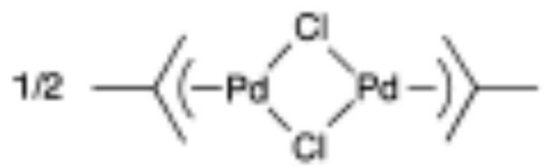

D1

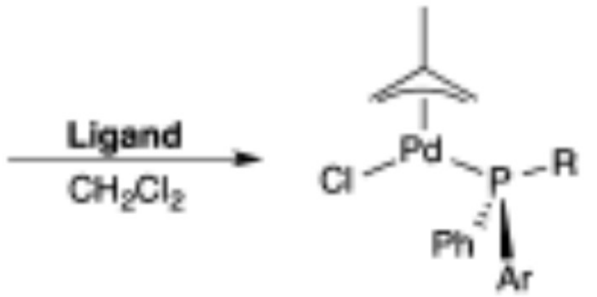

$\mathrm{R}=\mathrm{OMe}, 10$

$\mathrm{R}=\mathrm{M}_{\mathrm{\theta}}, 11$

$\mathrm{R}=f \mathrm{Pr}_{2} 12$ 
SCHEME 5

514

515
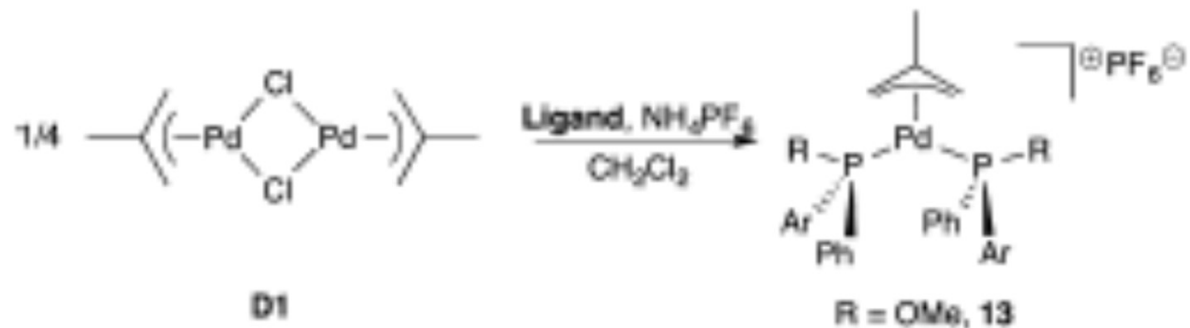

516

$\mathrm{R}=\mathrm{ON} \mathrm{B}_{1} 13$

$\mathrm{R}=\mathrm{Me}, 14$

517 
SCHEME 6

519

520
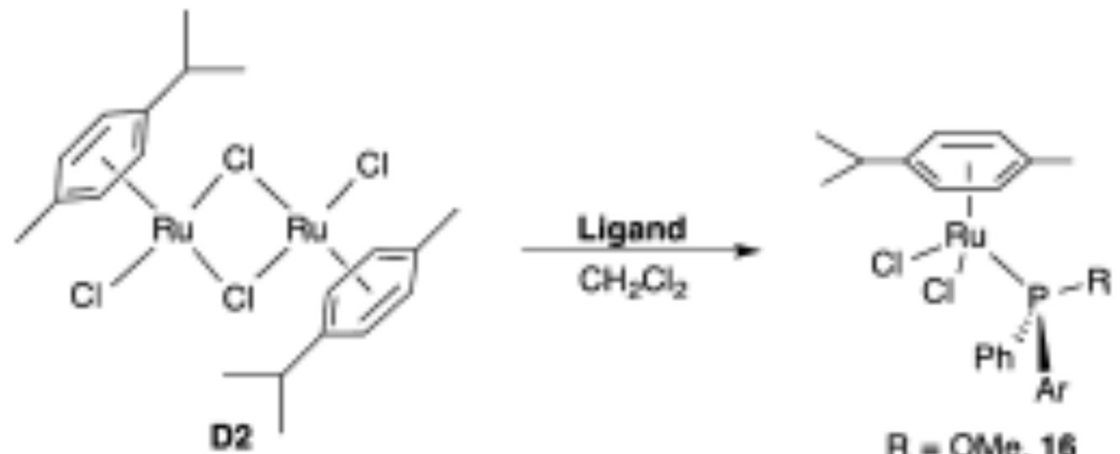

$\mathrm{A}=\mathrm{OMe}$, 16

$\mathrm{A}=\mathrm{Me}, 17$

$\mathrm{R}=\left\langle-\mathrm{Pr}_{1}, 18\right.$ 
524

525

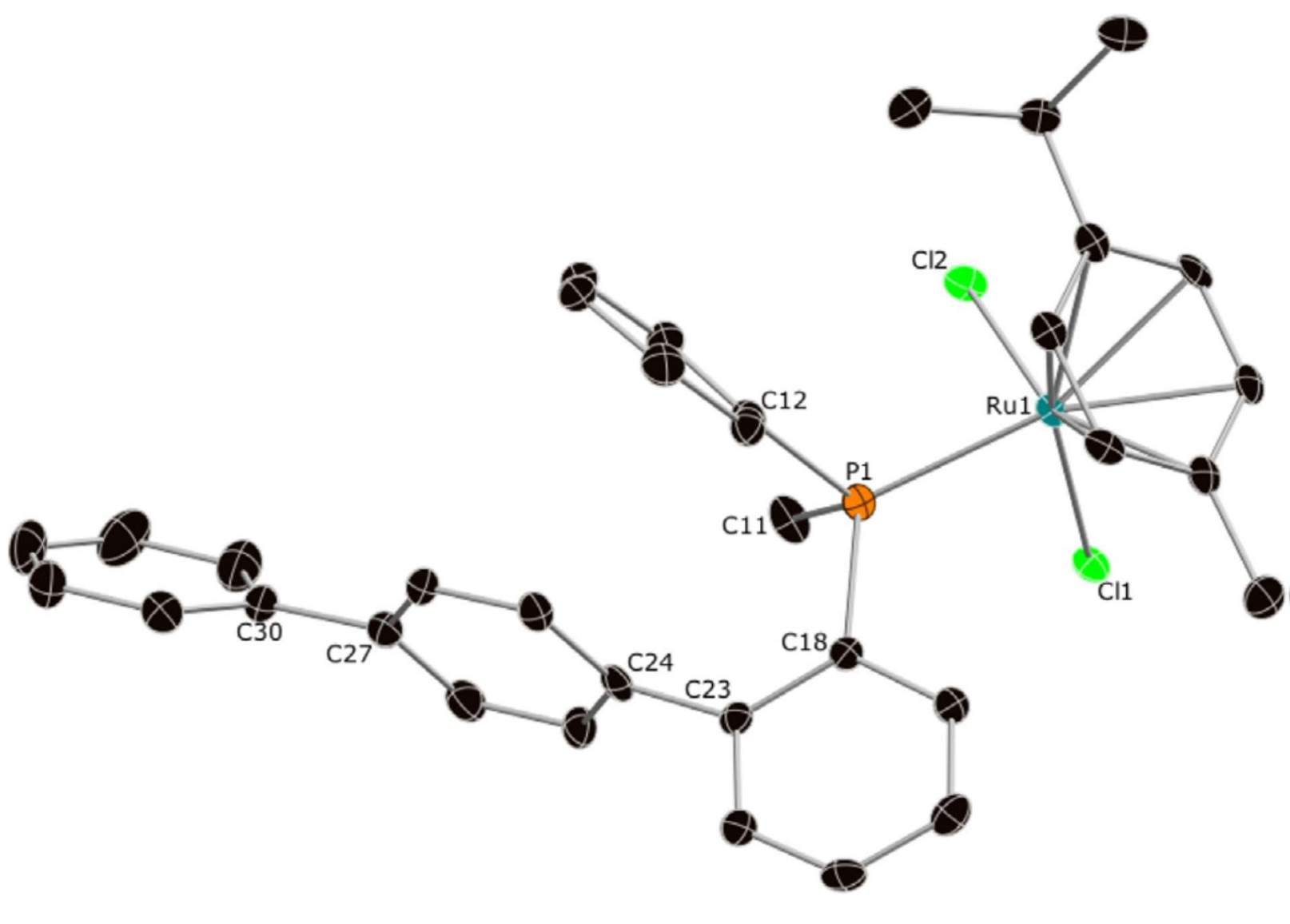

527 
528

529

530

SCHEME 7
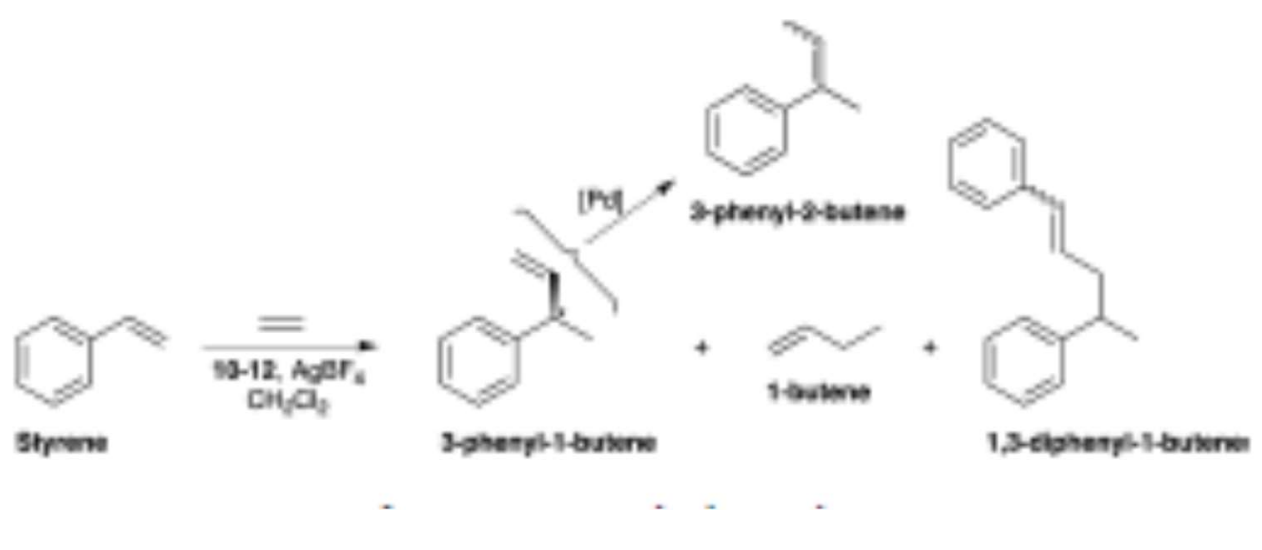

531

532 

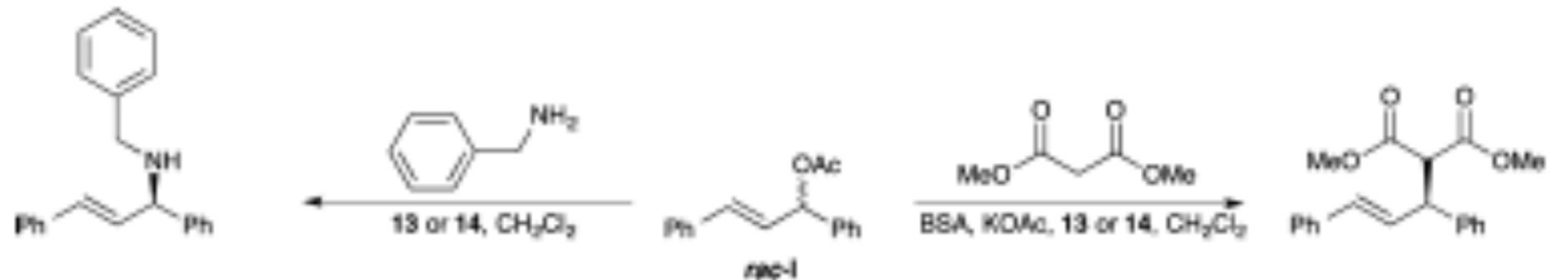

536

537 
540<smiles>CC(=O)c1ccccc1</smiles>

Acetophenone
16-18, KO-f-Bu<smiles>C[C@H](O)c1ccccc1</smiles>

1-phenylethanol 
543 Table 1 Styrene hydrovinylation catalysed with 10-12 complexes.

\begin{tabular}{|c|c|c|c|c|c|c|c|}
\hline Enitrya & Precursor & Time (h) & Conv. $^{b}(x)$ & Codimers' $(x)$ & Select. ${ }^{d}(x)$ & TOF" $\left(\mathrm{h}^{-1}\right)$ & $\operatorname{es}(z)$ \\
\hline 1 & $10 \mathrm{a}$ & 6 & 2.1 & 9.1 & $>99.9$ & 15 & $34(\mathrm{R})$ \\
\hline 2 & $10 \mathrm{~b}$ & 5 & 43.2 & 41.9 & 92.6 & 68 & $5(5)$ \\
\hline 3 & $11 \mathrm{a}$ & 6 & 23.1 & 228 & 95.0 & 38 & $19(5)$ \\
\hline 4 & $11 b$ & 6 & $\$ 999$ & 975 & 3.7 & - & - \\
\hline 5 & $11 \mathrm{~b}$ & 1 & 16.9 & 16.9 & $>99.9$ & 165 & $3(5)$ \\
\hline$\theta^{\prime}$ & $12 a$ & 6 & 626 & 62.6 & 95.8 & 105 & $43(5)$ \\
\hline
\end{tabular}

a Catalytic conditions: $25-\mathrm{C}$, 15 bar of initial pressure of ethylene in $15 \mathrm{~mL}$ of $\mathrm{CH}_{2} \mathrm{C}_{2}$. Katio styrene/ $/ \mathrm{Pd}=1000 / 1$.

b Conversion of starting styrene.

- Total amount of codimers

(1)

- TOF values calculated from the tntal amount of codimers formed. 
548 Table 2 Results of asymmetric allylic substitutions of rac-I with complexes 13 and 14.

\begin{tabular}{llllr}
\hline Entry & Nucleophile & Precursor & Corrversion $(\boldsymbol{z})^{p}$ & ee $(\boldsymbol{z})$ \\
\hline 1 & DMM & $13 \mathbf{a}$ & $>99$ & $80(\mathrm{~S})$ \\
2 & DMM & $14 \mathbf{a}$ & $>99$ & $<5$ \\
3 & DMM & $13 \mathbf{b}$ & $>99$ & $<5$ \\
4 & DMM & $14 \mathbf{b}$ & $>99$ & 7 (S) \\
5 & Berrylamine & $13 \mathbf{a}$ & $>99$ & $60(\mathrm{R})$ \\
6 & Berzylamine & $14 \mathbf{a}$ & $>99$ & $<5$ \\
7 & Berzylamine & $13 \mathbf{b}$ & $>99$ & $<5$ \\
8 & Berzylamine & $14 \mathbf{b}$ & $>99$ & $<5$ \\
\hline
\end{tabular}

${ }^{2}$ Catalytic conditions for allylic alkylations with dimethyl malonate: Pd complex (0.01 mmol), rac-1 (1 mmol), dimethyl malonate ( $3 \mathrm{mmol})$, BSA ( $3 \mathrm{mmol})$ and $\mathrm{KOAr}$ ( $1 \mathrm{mg}$ ) in $4 \mathrm{~mL}$ of $\mathrm{CH}_{2} \mathrm{Cl}_{2}$ at $\mathrm{rt}$ for $24 \mathrm{~h}$; for allylic substitutions with berzylamine: $\mathrm{Pd}$ complex ( $0.01 \mathrm{mmol}), \mathrm{rac}-1$ ( $1 \mathrm{mmol})$ and berz) ylamline ( $3 \mathrm{mmol})$ in $4 \mathrm{~mL}$ of $\mathrm{CH}_{2} \mathrm{Cl}_{2}$ at it for $24 \mathrm{~h}$.

b Conversion percentage expressed as rac-I consumption, determined by NMR and HFLC.

" Enantiomeric excesses determined by HPLC. 
555 Table 3. Hydrogen transfer of acetophenone catalysed by complexes 16-18.

556

\begin{tabular}{|c|c|c|c|c|}
\hline Entry ${ }^{2}$ & Precursor & Time (h) & Conversian $(\boldsymbol{z}) \boldsymbol{p}$ & $\operatorname{ce}(\boldsymbol{x})$ \\
\hline 1 & 161 & $1 / 3 / 5 / 24$ & $9 / 29 / 48 / 99$ & $<5$ \\
\hline 2 & $17 a$ & $1 / 3 / 5 / 24$ & $11 / 29 / 41 / 99$ & $<5$ \\
\hline 3 & $18 \mathbf{a}$ & $1 / 3 / 5 / 24$ & $12 / 29 / 42 / 99$ & $12(\mathrm{R})$ \\
\hline 4 & $16 \mathrm{~b}$ & $1 / 3 / 5 / 24$ & $43 \sqrt{72 / 85} / 99$ & 9 (s) \\
\hline 5 & $17 \mathrm{~b}$ & $1 / 3 / 5 / 24$ & $8 / 24 / 39 / 83$ & $6(\mathrm{R})$ \\
\hline
\end{tabular}

a Catalytic conditions: Ru cumplex (0.02 mmal) and t-BuCKK ( $0.1 \mathrm{mmol})$ dissalved in $25 \mathrm{~mL}$. of $\mathrm{i}-\mathrm{PrOH}$ and activated at 82 - $\mathrm{C}$ during $15 \mathrm{~min}$ before adding acetophenone (4.0 mmol)

${ }^{b}$ Conversion of starting acetophenone.

c Enantiomeric excess at $24 \mathrm{~h}$. 